\title{
The Location and Function of NMDA Receptors in Cat and Kitten Visual Cortex
}

\author{
Kevin Fox, Hiromichi Sato, and Nigel Daw \\ Department of Cell Biology and Physiology and the McDonnell Center for Studies of Higher Brain Function, Washington \\ University School of Medicine, St. Louis, Missouri 63110
}

The role of N-methyl-D-aspartate (NMDA) receptors in cat visual cortex was studied as a function of both layer and age by iontophoresis of the NMDA antagonist (D)-2-amino5-phosphonovaleric acid (APV). Effects on both visual responses and spontaneous activity were observed. In superficial layers (II and III), D-APV reduced visual responses substantially at all ages. Iontophoresis of D-APV with $10 \mathrm{nA}$ of ejecting current for 2-3 min was sufficient to reduce the response to approximately one third of control levels. The magnitude of the reduction did not vary with age. In granular and deep layers (IV, V, and VI), D-APV affected the visual response in young animals but only spontaneous activity in older animals. On average, visual responses were reduced to about half at 20-23 days of age and to about $75 \%$ at 4 weeks of age but in most cases were not signiticantly affected in adults.

The rapid change in the functional effect of NMDA receptors over the third and fourth week in granular and deep layers suggests a role in development. There was a reasonable age correlation between the change in effect and the period of geniculocortical afferent segregation. Further experiments will be necessary to determine whether NMDA receptors are necessary for segregation to occur. The presence of an NMDA component to the visual response in the adult in layers II and III argues either that these layers retain some form of plasticity in the adult or that NMDA receptors play a role in the transmission of normal visual input to these layers.

N-methyl-D-aspartate (NMDA) receptors have been implicated in the control of connectivity during development. Implantation of a third eye in the immature frog results in an adult tectum in which afferents from 2 of the 3 eyes segregate into regular bands: this process of segregation is prevented by the NMDA antagonist (D)-2-amino-5-phosphonovaleric acid (APV) (Cline et al., 1987). In the kitten visual cortex, monocular deprivation leads to a shift in the influence of the 2 eyes. The experienced eye becomes the dominant input to cells recorded in the visual cortex (Wiesel and Hubel, 1963). This shift in ocular dominance

\footnotetext{
Received Sept. 22, 1988; revised Dec. 19, 1988; accepted Dec. 27, 1988.

This work was supported by PHS grants EY00053, NS18070, and the McDonnell Center for Studies of Higher Brain Function. We wish to thank Marla Luskin for advice regarding the histology of immature kitten cortex, Janice Watkins for preparing the sections, Gavin Perry for the analysis software, and Larry Trussel for helpful criticism of the text.

Correspondence should be addressed to K. Fox, Ph.D., Department of Cell Biology and Physiology, Washington University School of Medicine, Box 8101, 660 S. Euclid Ave., St. Louis, MO 63110.
}

Copyright @ 1989 Society for Neuroscience $0270-6474 / 89 / 072443-12 \$ 02.00 / 0$ is prevented by infusion of APV into the visual cortex (Kleinschmidt et al., 1987).

The effects of visual deprivation on development of the visual cortex are generally specific to the deprivation. Monocular deprivation leads to a decrease in the influence of the deprived eye without changes in orientation or direction selectivity (Wiesel and Hubel, 1963); orientation or direction deprivation leads to changes in direction specificity without altering the balance of inputs from the 2 eyes (Blakemore and Van Sluyters, 1975; Berman and Daw, 1977). However, infusion of APV has a more general effect on the properties of cells when combined with monocular deprivation, as it produces cells with nonspecific receptive fields as well as preventing shifts in ocular dominance (Kleinschmidt et al., 1987). It is not clear whether the effect of APV in these cases is confined to blocking a mechanism necessary for plasticity, or blocking a more fundamental function such as normal sensory processing. Procedures which produce a general depressant effect on activity in the visual cortex are known to prevent the effects of monocular deprivation, including anesthesia (Freeman and Bonds, 1979) and blocking activity with TTX (Reiter et al., 1986). Further experiments are clearly needed, therefore, to test whether NMDA receptors have a specific role in plasticity during the critical period for the development of the visual cortex.

We explored this problem by studying the effect of the NMDA antagonist APV on visual responses of area 17 (A17) neurons in cats and kittens of different ages. If NMDA receptors are involved with visual processing per se, APV might be expected to suppress some component of the visual response, and the effect should be relatively constant at different ages. If, on the other hand, the absence of functional NMDA receptors were to limit the plasticity of a neuron, one would expect to find functional NMDA receptors in kitten cortex during the critical period but not later on in adults.

One study has reported a difference between NMDA receptors in kittens and cats when results from all cortical layers were combined for comparison (Tsumoto et al., 1987). However, since the critical period is different for granular and extragranular layers in the kitten visual cortex (Mower et al., 1985), we wished to investigate how the influence of NMDA receptors differed between kitten and adult A17 neurons for individual cortical layers. The critical period for layer IV ends earlier than for other layers. Consequently, if the main function of NMDA receptors is to play a crucial role in plasticity, one would expect their efficacy to decline in the middle of the critical period in layer IV and toward the end of the critical period in other layers. Wc thereforc studicd the effects of APV on visual responses and spontaneous activity of 3 age groups of cats: 20-23 days, 28- 
35 days, and adults. Results for different layers were analyzed independently. The results were surprising and suggested that the role of NMDA receptors is more complicated than predicted by any of the theories advanced so far.

\section{Materials and Methods}

Surgery. Recordings were made from 12 kittens aged $28-35 \mathrm{~d}$ and 5 aged $20-23 \mathrm{~d}$. Nine adults aged between 7 months and 3 years were studied for comparison. Each animal was sedated with acepromazine $(0.46 \mathrm{mg} / \mathrm{kg}$ body weight; Aveco, Fort Dodge, IA) and given a preanesthetic dose of atropine $(0.5 \mathrm{mg} / \mathrm{kg})$. Anesthesia was induced with $4 \%$ halothane in a mixture of $66 \%$ nitrous oxide and $34 \%$ oxygen. After tracheotomy and intravenous cannulation, the ears were locally anesthetized with viscous lidocaine (International Medical Systems, El Monte, $\mathrm{CA})$ and the animal placed in a stereotaxic frame. The animal's retinae were focused on the screen with contact lenses. The pupils were dilated with atropine methyl nitrate. A rectangle of skull was removed over the postlateral gyrus, between AP0 and P5, extending 3 or $4 \mathrm{~mm}$ lateral from the midline. A small slit was made in the dura medial to the crown of the gyrus for electrode penetrations. After surgery the animal was paralyzed with intravenous infusion of pancuronium bromide (Pavulon; Organon Diagnostics, West Orange, NJ) and anesthesia maintained with approximately $0.7 \%$ halothane. Temperature was maintained at $37.5^{\circ} \mathrm{C}$ with a heating pad controlled by a rectal thermometer. Heart rate and expired $\mathrm{CO}_{2}$ were continuously monitored, with $\mathrm{CO}_{2}$ being maintained between 3.0 and $4.2 \%$.

Electrodes. Three barrel carbon fiber microelectrodes were constructed as described previously (Armstrong-James et al., 1980), except that $10 \mu \mathrm{m}$ Thornel carbon fibers were used (Amoco). These gave similar low noise recordings but seemed to improve spike amplitude over $7 \mu \mathrm{m}$ fibers. In some experiments 7-barrel electrodes were made from commercially available blanks (FHC, Brunswick), allowing several drugs to be used; any unused barrels were filled with saline. The center barrel contained the carbon fiber. These electrodes were found to penetrate the pia of all but the most mature animals. In the latter cases a small hole was made in the pia prior to introducing the carbon fiber microelectrode by inserting a tungsten microelectrode at an oblique angle to that of the recording penetration. The exposure was protected with $2 \%$ agar dissolved in $0.9 \%$ saline once the electrode was in place.

Recordings. Single unit recordings were made from all layers, and each recording location marked with a small focal lesion $(2 \mu \mathrm{A}, 10 \mathrm{sec}$, tip negative). Neurons were sampled at approximately $300-\mu \mathrm{m}$ intervals throughout the penetration. The electrode having been moved to a new position, a hand-held projector was used to stimulate the cell. If the recording isolation was inadequate, the electrode was advanced in small $(20 \mu \mathrm{m})$ steps until an improvement was found. Receptive fields were characterized and plotted on a tangent screen. The optimal stimulus direction, velocity, length, and width of a bar of light were determined and used to stimulate the cell via the dominant eye. Visual stimuli were applied by an optical bench under computer control. Spikes were discriminated through a voltage window and monitored for amplitude and timecourse on a digital storage oscilloscope (Hameg HM208, Port Washington, NY). Spike discharge times were recorded via an 80286 based microcomputer (PC's Ltd.) using a Datalab data acquisition board (Tecmar, Cleveland, $\mathrm{OH})$. Peristimulus time histograms were displayed online, enabling us to monitor response stability. Spike times were stored on hard disk for subsequent off-line analysis using custom-written Asyst programs (Asyst Software, Rochester, NY). In the agonist/antagonist interaction experiments, spike events were directly summed in 4-sec bins and the bin counts stored on disk. For all other experiments spike times were recorded, allowing us to analyze data off-line in several different ways.

Visual stimulus. The computer-controlled visual stimulus was a moving bar of light swept across the receptive field at the optimal velocity. One second of spontaneous activity was recorded before the start of each sweep. Having moved through the receptive field in one direction, the light-bar paused for $1 \mathrm{sec}$ beyond the receptive field before sweeping back in the reverse direction. Four stimuli were applied per minute, each stimulus sweep separated by 2 sec. Depending on the stimulus velocity, the fraction of a minute occupied by stimulation varied from $25 \mathrm{sec}$ to $50 \mathrm{sec}$. The visual stimuli were applied continuously throughout the experiment.

Iontophoresis. All drugs were dissolved in distilled water at the following concentrations: NMDA $20 \mathrm{~mm}$, kainate $50 \mathrm{~mm}$ (Sigma, St. Louis,
MO), quisqualate $50 \mathrm{~mm}$ (Research Biochemicals, Natick, MA), D-APV $50 \mathrm{~mm}$ (Tocris, Buckhurst Hill, UK), adjusted to pH 7.4-8.0. Effective retain currents were typically $3-6 \mathrm{nA}$ with these electrodes. The visual response of each cell was tested for its sensitivity to NMDA and APV (various additional trials were conducted in most cases): (1) Visual stimuli were applied continuously throughout the experiment. After collecting control responses, (2) NMDA was ejected (usually at 10-20 $n A$ ) until the cell became excited (mainly an increase in spontaneous activity). The current was then reduced to a level where the excitation seemed stable. (3) APV was ejected at $20 \mathrm{nA}$ until it began to antagonize the NMDA-induced effect. This was first signified by a reduction in the NMDA-induced spontaneous activity. (4) As soon as the antagonism started, the NMDA was retained and the APV ejecting current reduced to $10 \mathrm{nA}$ for $2 \mathrm{~min}$, then retained. (5) After recovery, which could take longer in some cells than in others (2-10 min), APV was again tested on its own. A current of $20 \mathrm{nA}$ was applied for 1 min followed by 10 $\mathrm{nA}$ for a further $2 \mathrm{~min}$. The APV was then retained. (6) If the visual response of the cell did not appear to be affected by the above procedure, then APV was ejected at $20 \mathrm{nA}$ for $3 \mathrm{~min}$, and, if there was still no effect, at $30 \mathrm{nA}$ for 3-5 min.

Analysis of data. When the cells were analyzed off-line, the following criteria were used to assess the significance and reliability of the data recorded during the drug trial. (1) The control level of visual responses, assessed over $5 \mathrm{~min}$ ( 20 stimuli), though occasionally 3 or $4 \mathrm{~min}$, must have exhibited a coefficient of variation (SD/mean) of less than 0.2 . (2) The visual response was considered to have been affected by APV if (a) the mean response during the second and third minute of trial was at least one standard deviation from the mean of the control and (b) the cell eventually recovered to within at least $75 \%$ of the mean control level after the APV trial.

As a consequence of criteria 1 and 2(a), decreases to $80 \%$ of control were at the limit of significance for the cells with the most variable responses. Where cells met the above criteria, a value of percentage suppression was calculated for response to APV by expressing the mean visual response during the $2 \mathrm{nd}$ and $3 \mathrm{rd}$ min of the trial as a percentage of the mean control level (see Fig. 3). The visual response was considered to be the total number of spikes occurring above the background level while the visual stimulus was moving through the receptive field. If a cell was bidirectional, responses in both forward and reverse directions were summed and considered as the visual response. Most cells had a response $(R)$ to spontaneous $(S)$ activity ratio of at least 9 , where

$$
R / S=\frac{\text { visual response }- \text { spontaneous activity }}{\text { spontaneous activity }}
$$

Binocularity index. The extent to which the cortex tended to be binocular was estimated using a binocularity index (BI) as follows:

$$
\mathrm{BI}=\frac{1 / 3[G 2+G 6]+2 / 3[G 3+G 5]+G 4}{G 1+G 2+G 3+G 4+G 5+G 6+G 7}
$$

Where group one $(G l)$ is the number of cells responding to just the contralateral eye, $G 7$ those responding to just the ipsilateral eye, and $G 2$ to $G 6$ degrees of binocular input in between, $G 4$ being equal input from both eyes.

Lesions and histology. Small focal lesions were made through the recording electrode using $2 \mu \mathrm{A} \mathrm{DC}$ current for $10 \mathrm{sec}$ (tip negative). Lesions were usually $50-100 \mu \mathrm{m}$ diameter and were characterized by gliosis. Higher currents of 3-3.5 $\mu \mathrm{A}$ were used for lesions made within $3 \mathrm{hr}$ of perfusion, as gliosis was reduced in these cases. On completion of the experiment, the animal was deeply anesthetized before transcardiac perfusion. An injection of heparin preceded 300-500 ml PBS followed by $500-1000 \mathrm{ml} 10 \%$ buffered formalin. The gyrus containing the penetrations was removed and allowed to sink in $15 \%$ sucrose. Frozen sections were cut $(60 \mu \mathrm{m})$ and stained with thionin or cresyl violet.

\section{Results}

\section{Neuron sample}

A total of 197 cells were recorded from A17 and their receptive field properties characterized. Of these, 160 were considered 
stable enough to study at the time of the experiment. After offline analysis, 125 cells met the criteria for response stability, showed adequate recovery (see Materials and Methods), and could be clearly assigned to a particular cortical layer: these cells are the subject of this report.

It usually was possible to identify whether a cell was located in layer II rather than in layer III; most layer II recordings were conducted just below layer I, whereas layer III recordings were at the level of the large pyramidal cells. No distinction was made between layers II and III for the 20-23 d animals, as the superficial layers were clearly immature, exhibiting a zone of compact cells at the top of the cortical plate. However, the layer III/ IV border was well defined in the $20-23 \mathrm{~d}$ age group.

\section{Specificity of the D-APV "dose"}

It was necessary to test whether the "dose" of APV delivered by these electrodes was selective for NMDA receptors. The specificity of APV was tested at twice the ejecting current used against visual responses $(20 \mathrm{nA}$ rather than $10 \mathrm{nA})$. The effect of $20 \mathrm{nA}$ APV applied for 2-3 min was tested on submaximal excitations induced by kainate and NMDA in 6 cells. Responses to kainate were unaffected by APV in 5 cases (within $20 \%$ of control), whereas responses to NMDA were reduced to $10 \%$ of control. In the other case, APV reduced the kainate excitations to $73 \%$ of control and the NMDA-induced excitation to $13 \%$. Figure 1 shows the procedure for this type of experiment. Three approximately equal pairs of responses to kainate and NMDA are followed by a fourth pair during simultaneous application of APV. The response in each case is considered to be the number of spikes above background (the area under the curve), as peak firing rate is too dependent on exact eject and retain times. The agonists are applied at regular intervals and control, test, and recovery periods are contiguous to allow comparisons to be made. This avoids artifacts caused by applying retain currents of variable duration between trials, which has a marked effect on drug concentrations during subsequent ejections (Kruk et al., 1980).

The effect of APV was also tested on excitations induced by quisqualate in 6 cells. An example can be seen in Figure 1. It was found that applications of APV were highly selective for NMDA compared with quisqualate receptors. In 5 cells, responses to quisqualate application were unaffected by APV, whereas NMDA-induced excitations were reduced to between 0 and $12 \%$ of control values. In the remaining case, APV applied with $20 \mathrm{nA}$ ejecting current decreased the quisqualate-induced excitation to $73 \%$ and the NMDA-induced excitation to $4 \%$ of control.

\section{Effectiveness of the APV dose}

The ejecting current parameters were chosen to ensure specificity of the dose of APV. However, since iontophoresis entails applying drugs from a point source, a compromise is made between keeping the dose small enough to be specific yet large enough to cover a substantial proportion of the cell's dendrites. In all 125 cases, it was clear that APV reached an effective concentration over an influential proportion of the cells' NMDA receptors. Firstly, APV always reduced the spontaneous activity of a neuron, even in cases where the visual response was unaffected. Secondly, APV always affected NMDA receptors which were themselves capable of causing a 2- or 3-fold increase in spontaneous activity when stimulated directly with NMDA.

In all cases where APV had an insignificant or a significant but small effect on the visual response, further tests were made with higher ejecting currents and/or longer durations of ejecting current. However, in no case was it found that APV caused a greater suppression of the visual response at a higher dose.

The exact extent of drug diffusion remains a matter of speculation until the appropriatc mcasurements are carried out; however, some estimate can be made. Experiments using electrochemical detection of iontophoresed noradrenaline suggest that ion flux reaches steady state after about $60 \mathrm{sec}$ with these electrodes (Kruk et al., 1980). We do not know the concentration of APV at the tip of our electrodes at steady state, but by comparison with catecholamine iontophoresis from the same electrodes, a $10 \mathrm{nA}$ ejecting current results in a tip concentration of about $5 \times 10^{-5} \mathrm{M}$ (Armstrong-James et al., 1981). Since drug concentration falls by $2 \log$ units over a distance of $230 \mu \mathrm{m}$ in vitro (M. Armstrong-James and P. Goustas, unpublished observations), the concentration at this radius would be approximately $5 \times 10^{-7} \mathrm{M}$. However, owing to tortuosity, the concentration is likely to be greater in vivo; in the cerebellum, for example, 12 times greater for a given iontophoretic flux (Nicholson and Phillips, 1981). Hence, we estimate that the concentration of APV was approximately $6 \mu \mathrm{M}$ at a distance of 230 $\mu \mathrm{m}$ from the electrode tip. Bath-applied APV has been found effective at concentrations of $25 \mu \mathrm{M}$ in slice preparations (Artola and Singer, 1987). Therefore, we estimate that APV reached an effective concentration over a range greater than $100 \mu \mathrm{m}$ but probably less than $200 \mu \mathrm{m}$ from the electrode tip.

\section{Differences between cortical layers \\ Adults}

In adult cats, visual responses of layer II/III neurons were substantially reduced by D-APV at ejecting currents that had no effect on visual responses in deeper layers. Figure 2 (left) shows an example of a layer II cell where the visual response was reduced to $22 \%$ of the control level when APV was applied for 2 min using $10 \mathrm{nA}$ ejecting current. In total, layer II/III neurons had visual responses that were reduced to approximately one third of control levels [median $=30 \%$, interquartile range (IQR) $=18 \%$, mean $=31 \%, n=21]$.

Neurons in deeper layers of cortex behaved in a markedly different way. Figure 2 (right) shows an example of a layer VI neuron with simple receptive field properties in which the visual response was unchanged during application of APV with $20 \mathrm{nA}$ (twice the normal ejecting current) while the spontaneous activity was substantially reduced. Such bchavior was characteristic of cells located in layers IV, V, and VI. In adults, 14 of 20 neurons in these layers showed no significant reduction in visual response in the presence of APV. Of the other 6 neurons that had reduced visual responses, none were suppressed below $53 \%$ of the control level. As a group these cells were relatively unaffected by APV (median $=100 \%, \mathrm{IQR}=24 \%$, and mean $=$ $89 \%$ of control). Increasing the ejecting current to 20 or $30 \mathrm{nA}$ had no further effect on cells that were unaffected by APV applied using $10 \mathrm{nA}$

The difference in sensitivity between superficial and deep layers was not an artifact due to a time-dependent deterioration in the iontophoresis barrels. When penetrations were angled down the medial bank so as to pass solely through superficial layers, similar results were obtained for the first and last cells encountered. In some penetrations the electrode was driven down directly to deeper layers so that the first cell studied was in layer IV, V, or VI. In these cases the same result was obtained as 
Kainate and NMDA

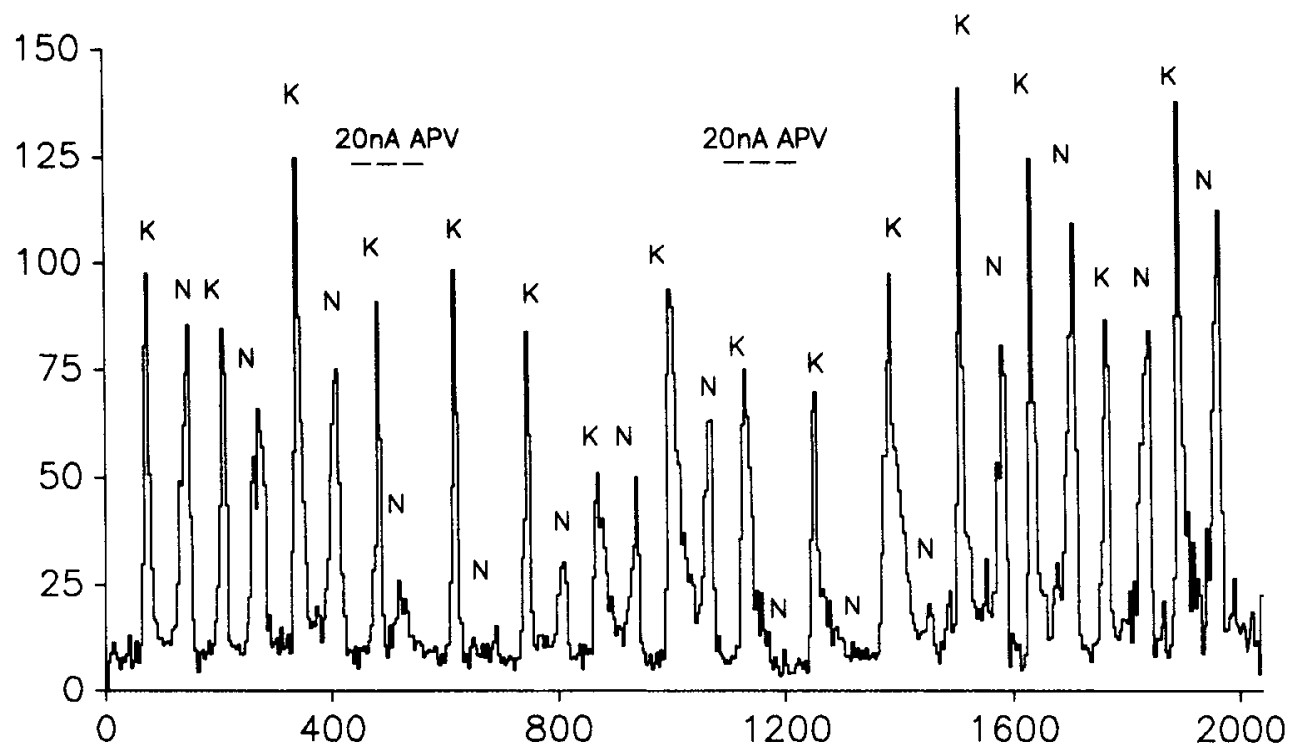

Quisqualate and NMDA

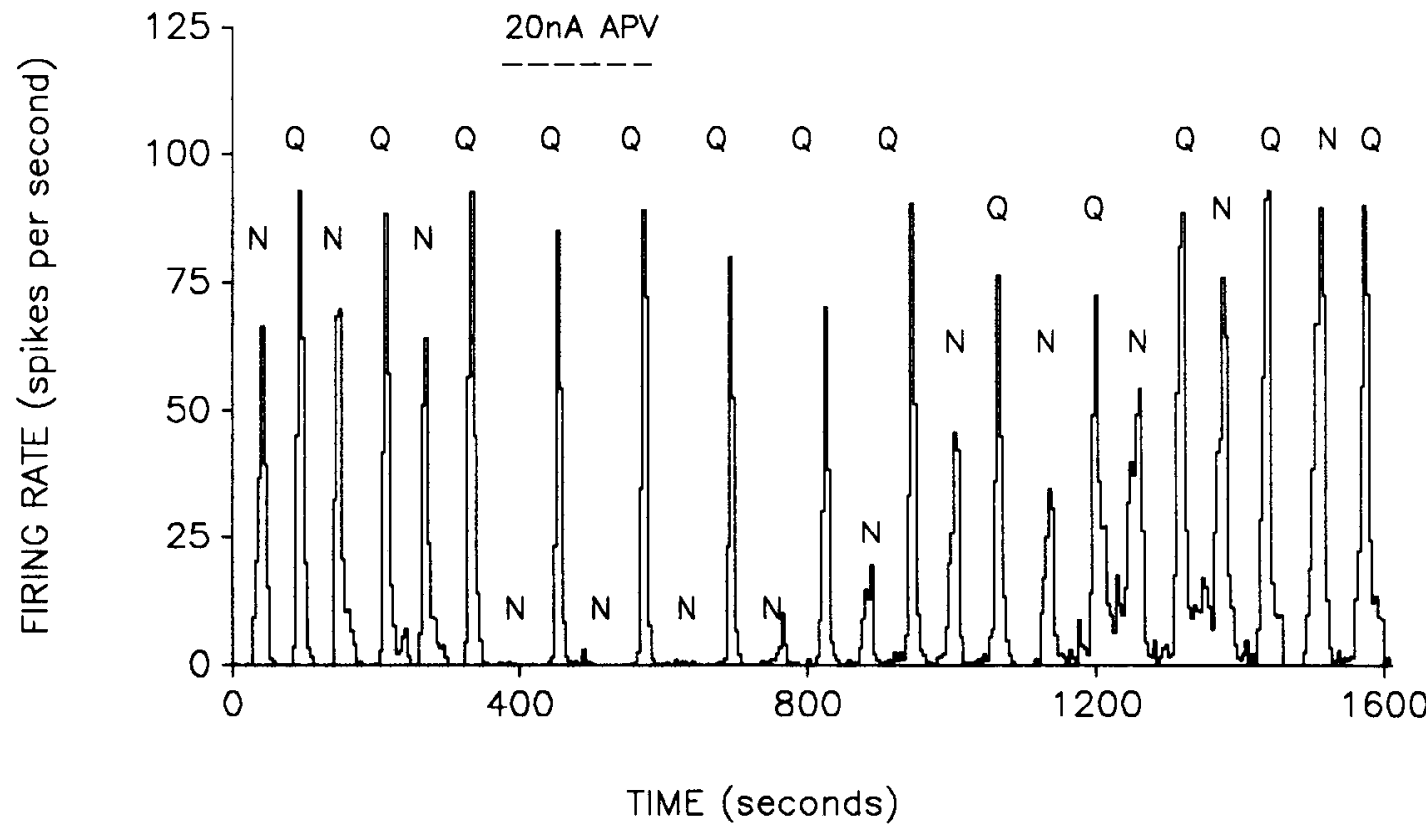

Figure 1. Effect of D-APV applied using $20 \mathrm{nA}$ ejecting current on NMDA-, kainate-, and quisqualate-induced excitation. Top. Applications of kainate $(20 \mathrm{nA}$ for $20 \mathrm{sec}$ ) were alternated with applications of NMDA ( $20 \mathrm{nA}$ for $35 \mathrm{sec}$ ) at regular intervals (every $70 \mathrm{sec}$ ). Three pairs of NMDA and kainate eject periods were followed by continuous application of APV with $20 \mathrm{nA}$ ejecting current for 140 sec during the fourth pair of agonist trials. The kainate-induced response was reduced to $80 \%$ of control and that due to NMDA to $6 \%$. After partial recovery, a second application of APV abolished the NMDA-induced response completely. Full recovery of the NMDA-induced excitation occurred within 6 min of terminating the second APV ejection. Bottom, Applications of quisqualate ( $20 \mathrm{nA}$ for $20 \mathrm{sec}$ ) were alternated with applications of NMDA (20 nA for 20 sec) at 50-sec intervals. A single application of APV was made for $200 \mathrm{sec}$ after 3 control pairs of agonist applications. The NMDA-induced effect was eliminated, whereas the response to quisqualate was unaffected. Recovery occurred within 9 min. (Areas rather than peaks are indicative of the magnitude of the response to the agonist.)

when the deeper layer cells were the third or fourth to be studied in the penetration. Finally, in cases where APV did not affect the cell's visual response, APV could nevertheless be shown to depress an NMDA-induced excitation (see Fig. 3) and spontaneous activity (see Figs. 2, 5, and 7).

\section{8-35 d kittens}

The difference in the susceptibility of visual responses in layers II and III compared with deeper layers was also detectable in the $28-35 \mathrm{~d}$ kittens. As with the adults, a value representing the 
Layer II Adult
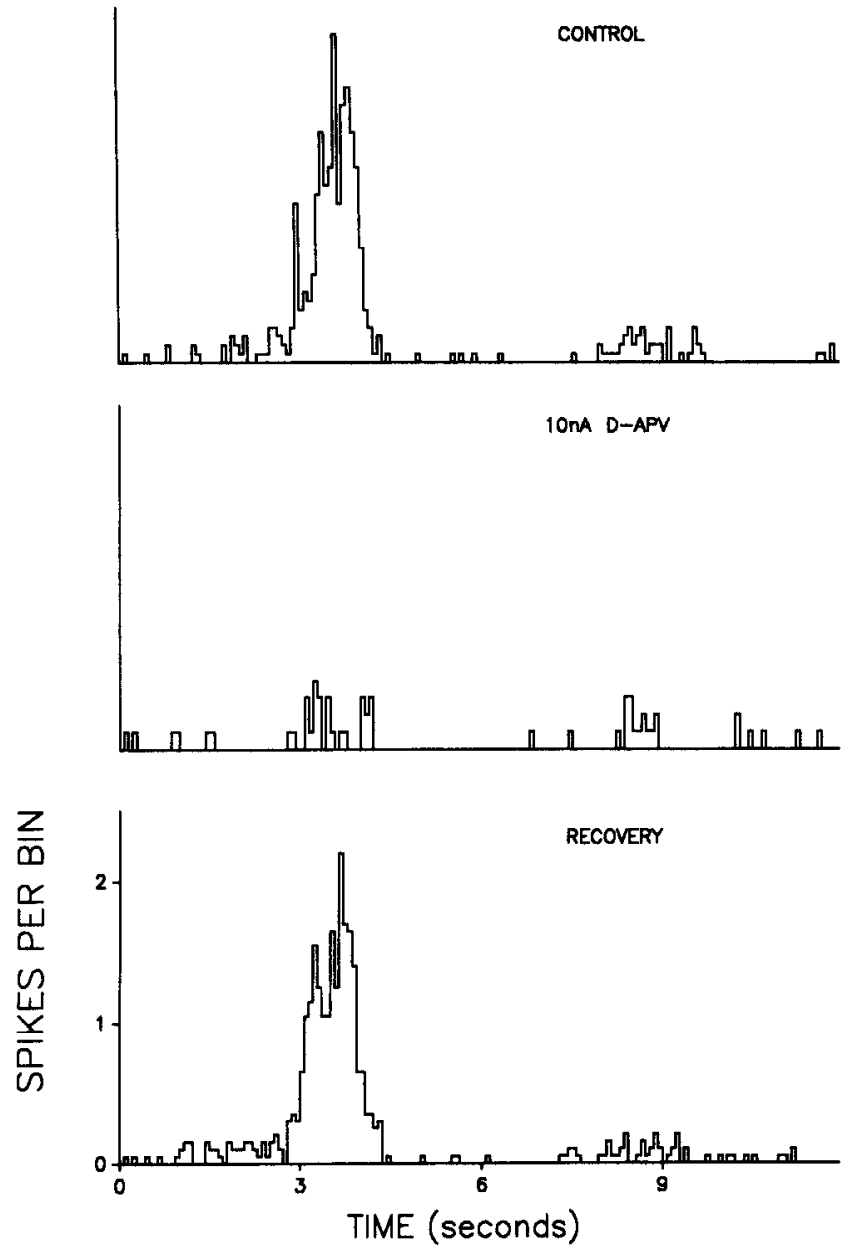

Layer VI Adult
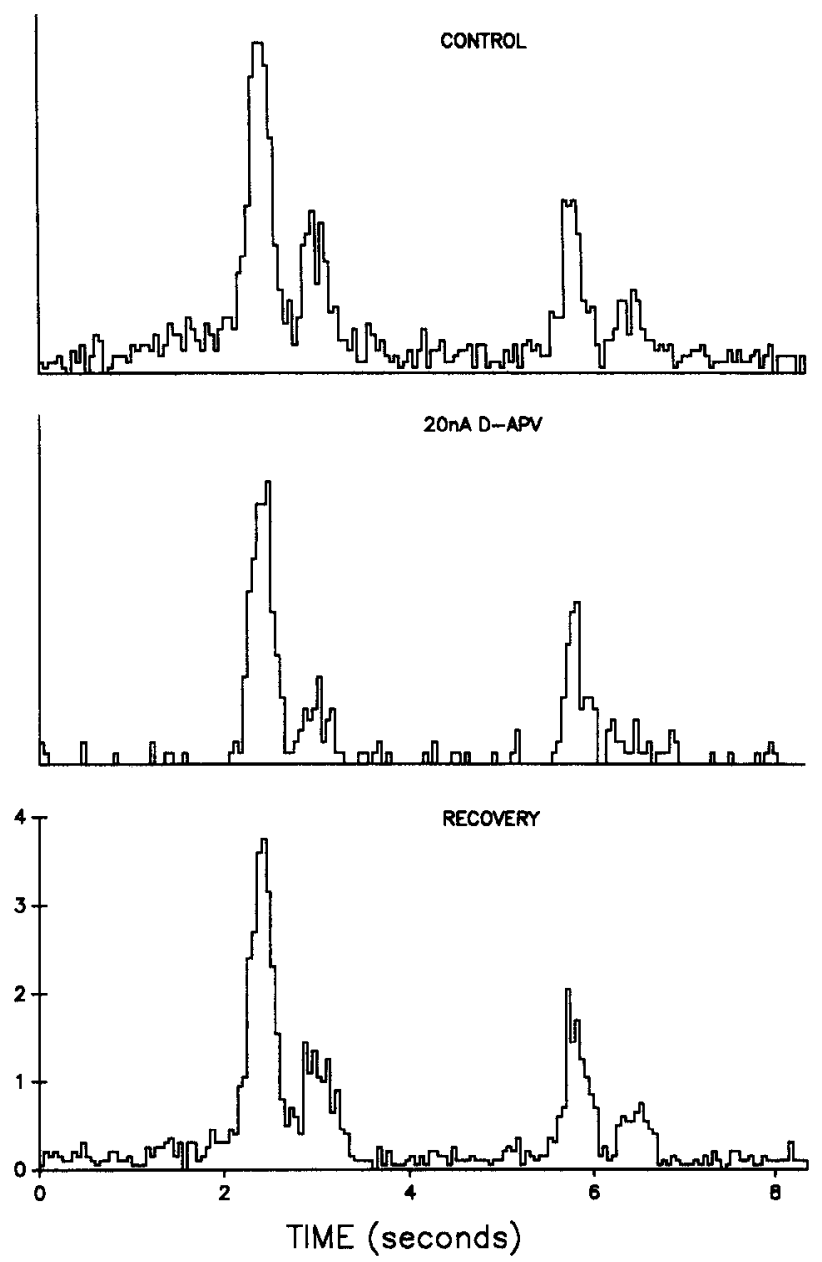

Figure 2. Effect of APV on single-unit responses of A17 neurons in adult cats. Control, test, and recovery peristimulus time histograms were recorded for a layer II cell (left column) and a layer VI cell (right column). Each control and recovery trace is an average of 20 stimulus sweeps presented over $5 \mathrm{~min}$. The drug trial histograms (center) are averages of 8 stimuli presented during the second and third minute of drug application. The stimulus was a moving bar of light swept first in one direction (first response peak) and then the reverse (second response peak) across the receptive field. The stimulus was stationary outside the receptive field for the first and last second of the trace. Bin width is 50 msec. Left, Layer II complex cell. The visual response was reduced to $22 \%$ of control. Recovery to $115 \%$ of control assessed from 5 to 10 min post-drug application. A second trial (not shown) immediately after recovery produced similar results: reduction to $24 \%$ of control, recovery to $106 \%$ within 7 min. Right, Layer VI simple cell. The visual response was marginally reduced (to $73 \%$ of control). Note the decrease in spontaneous activity (to $20 \%$ of control). Recovery occurred within 4 min of retaining APV. A subsequent trial using $30 \mathrm{nA}$ ejecting current did not cause any greater decrease in the visual response.

sensitivity of the visual response to suppression by APV was calculated for each neuron. The method is illustrated in Figure 3 (see Materials and Methods for details). The total number of spikes evoked by 4 visual stimuli is plotted against time. The 4 or 5 groups of stimuli preceding the iontophoresis trial (1620 stimuli) were averaged to give a mean control response. The mean visual response during the second and third minutes of APV iontophoresis was similarly evaluated and expressed as a percentage of the mean control response. Provided the neuron recovered its visual response to greater than $75 \%$ of control, the coefficient of variation for the control period was less than 0.2 , and the control period did not show a trend up or down, the "percentage suppression" was considered to summarize the drug trial. The test was always repeated at least once on each cell. Successive trials usually yielded similar results (within 10-20\%).
Where this was not the case the data was excluded from further analysis.

The top trace in Figure 3 shows a layer III neuron where the visual response was reduced by APV. It was found that neurons in layers II and III of 28-35 d kittens exhibited reductions in visual response similar to those found in adult cats. The visual responses of supragranular layer neurons were reduced to approximately one third of control levels (median $=20 \%, \mathrm{IQR}=$ $27 \%$, mean $=29 \%$ of control, $n=24$ ). The visual responses of layer IV, V, and VI neurons in 4-week kittens were less affected by APV than were those of supragranular neurons in the same animals. Figure 3 (bottom) shows an example of a neuron where 20 nA APV ejecting current did not alter the neuron's visual response despite having eliminated the NMDA-induced excitation $6 \mathrm{~min}$ previously at one third the duration of ejecting 

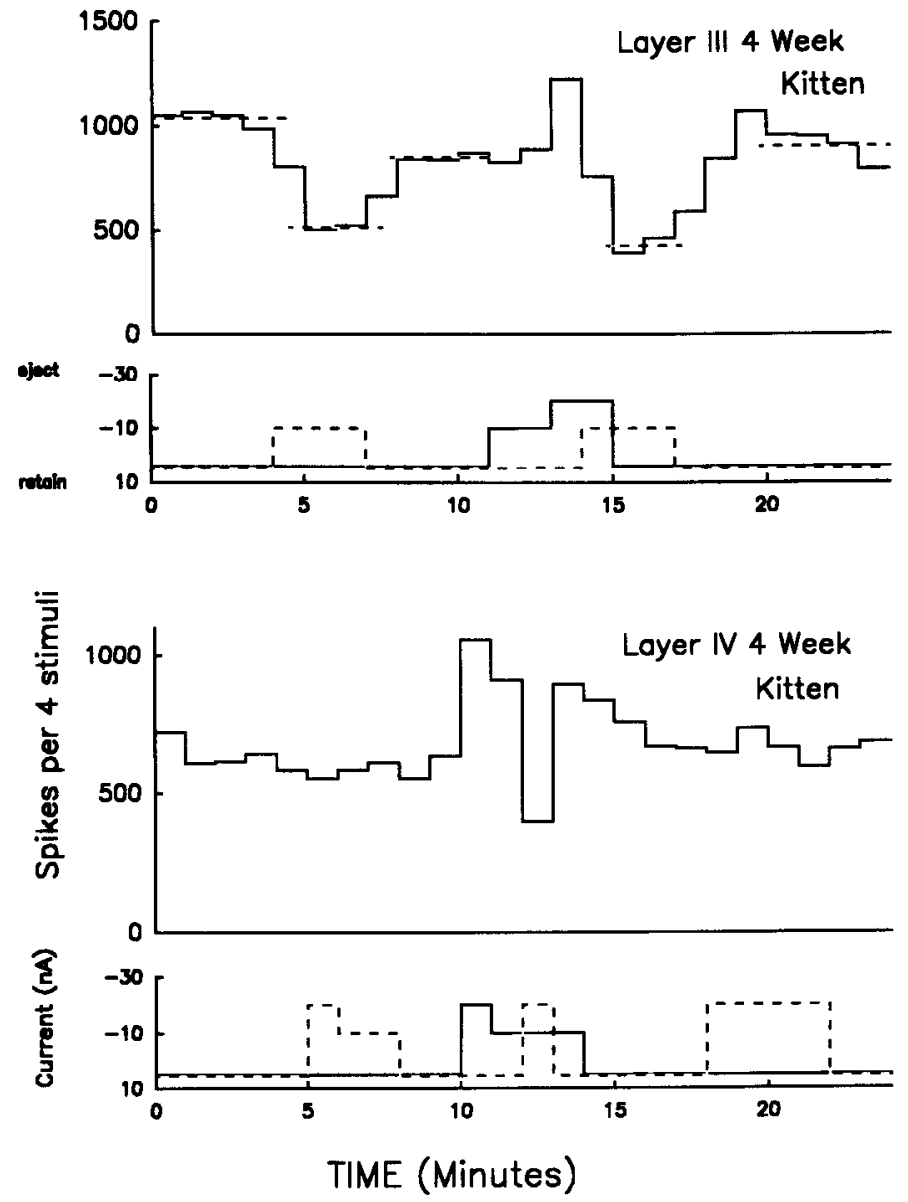

Figure 3. Effect of APV on single-unit responses of A17 neurons in 4-week-old kittens. Top trace of each pair represents the number of spikes produced in response to 4 stimuli presentations per $1 \mathrm{~min}$ bin. Broken lines in the topmost trace are mean values. Lower trace of each pair shows the corresponding iontophoretic currents applied to the APV (dashed line) and NMDA (solid line) barrels. Top, Layer III cell. Two APV applications of 3 min duration are shown. The second application occurred during excitation induced by NMDA. In the first trial the visual response was reduced to $50 \%$ of the mean control level and then recovered to $83 \%$ of control. In the second trial a reduction to $50 \%$ of the new control level was followed by a return to $105 \%$ of control. Bottom, Layer IV cell. Three APV trials are shown. The first and third applications did not affect the visual response. A short-duration application in between (second trial) was sufficient to antagonize the NMDA-induced excitation.

current. In 4-week kittens 11 of 26 neurons in deeper layers did not show a significant reduction of visual response in the presence of APV. In summary, visual responses of layer II and III neurons were more sensitive than those of layer IV, V, and VI neurons in $28-35 \mathrm{~d}$ animals and in adult cats.

\section{0-23 day kittens}

There were only small differences between layers in 3-week-old animals. Visual responses of neurons located in layers IV, V, and VI were almost as sensitive to blockade by APV as were superficial layer cells. Though the distributions for layer II/III cells and layer IV/V/VI cells overlapped, the centers of the distributions were separate (median $=45 \%, \mathrm{IQR}=17 \%$, mean $=48 \%$ for layers IV, V, and VI compared with $26 \%, 26 \%$, and $20 \%$, respectively, for layers II and III).

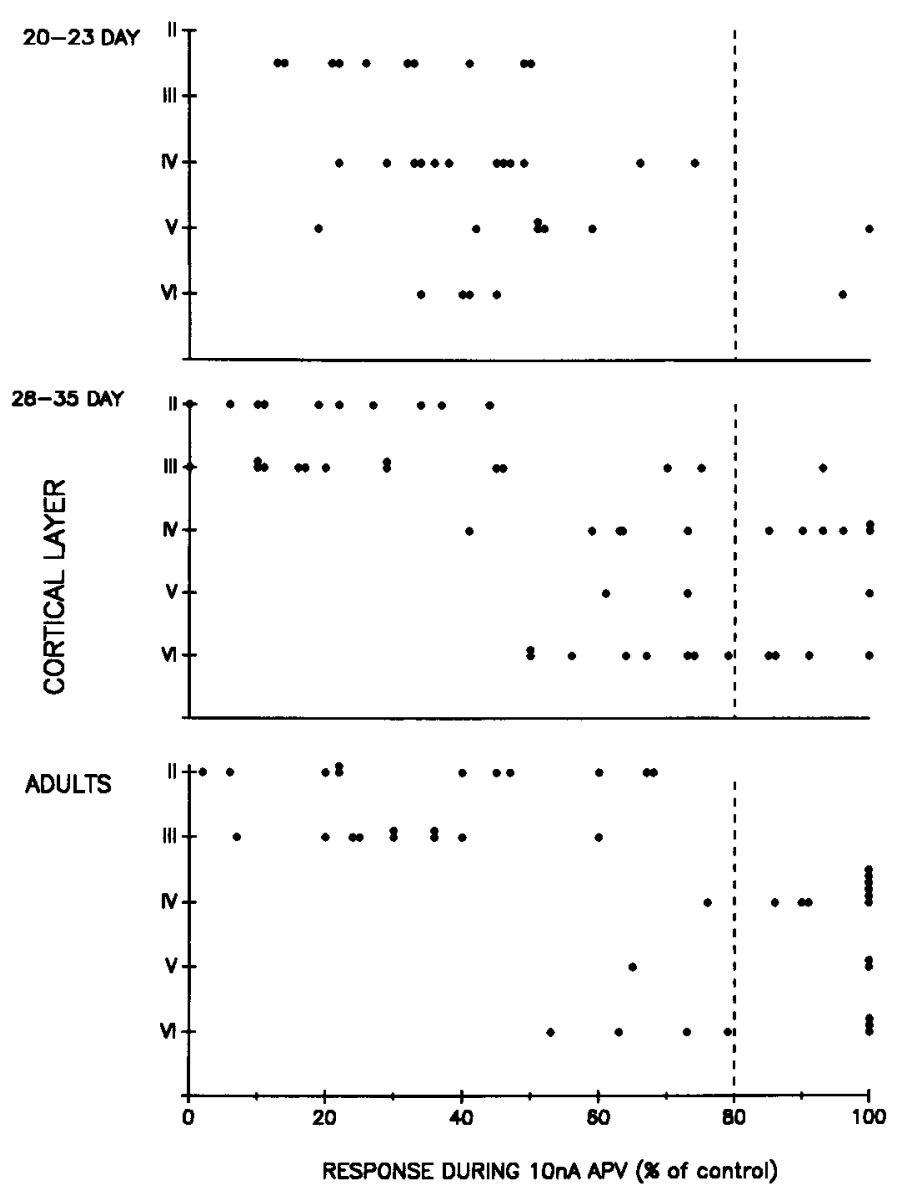

Figure 4. Effect of APV on visual responses in individual cortical layers for three age groups. Each point represents data from a single cell. The layer in which the cell was located is shown on the left of each graph. The mean visual response during $10 \mathrm{nA}$ application of APV is represented along the abscissa as a percentage of the mean control response. Hence cells unaffected by the drug lie on the far right edge $(100 \%)$. Broken line at $80 \%$ signifies the minimum change required for significance (see Materials and Methods). Top, 20-23 d age group. Most cells were affected by APV, with no obvious difference between layers. Cells positioned diagramatically between layers II and III were located in supragranular layers which were underdeveloped at this age. Middle, 28-35 d age group. A clear difference can be seen between layer II/III cells and those located in deeper layers. Visual responses of neurons in deep layers were less sensitive to APV than those in the 20-23 d age group. Bottom, Adult age group. The distribution was similar to the 28-35 d group, but the visual responses of deeper layer neurons were even less affected by APV. See text for numerical description.

\section{Differences between ages}

\section{Layers II and III}

Superficial layer neurons behaved similarly at all ages tested. Visual responses were substantially reduced by the standard "dose" of $10 \mathrm{nA}$ of APV for 2 min (see Materials and Methods) but were not completely eliminated. Figure 4 shows the distribution of visual response magnitudes (as a percentage of control) for neurons in different layers in the presence of APV. The distributions for layers II and III in all age groups overlap extensively. As a comparison of the populations the median values and IQRs were calculated. Medians were 30,20 , and $26 \%$ for adult cats, 4-week kittens and 3-week kittens, respectively; IQRs were 18,27 , and $20 \%$. These figures confirm that the distributions are similar, which validates combining the results. Thus, 
Layer IV 20 Days

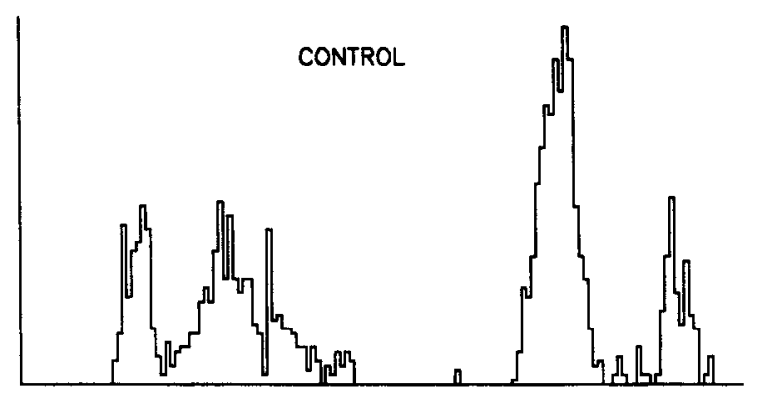

IONA D-APV
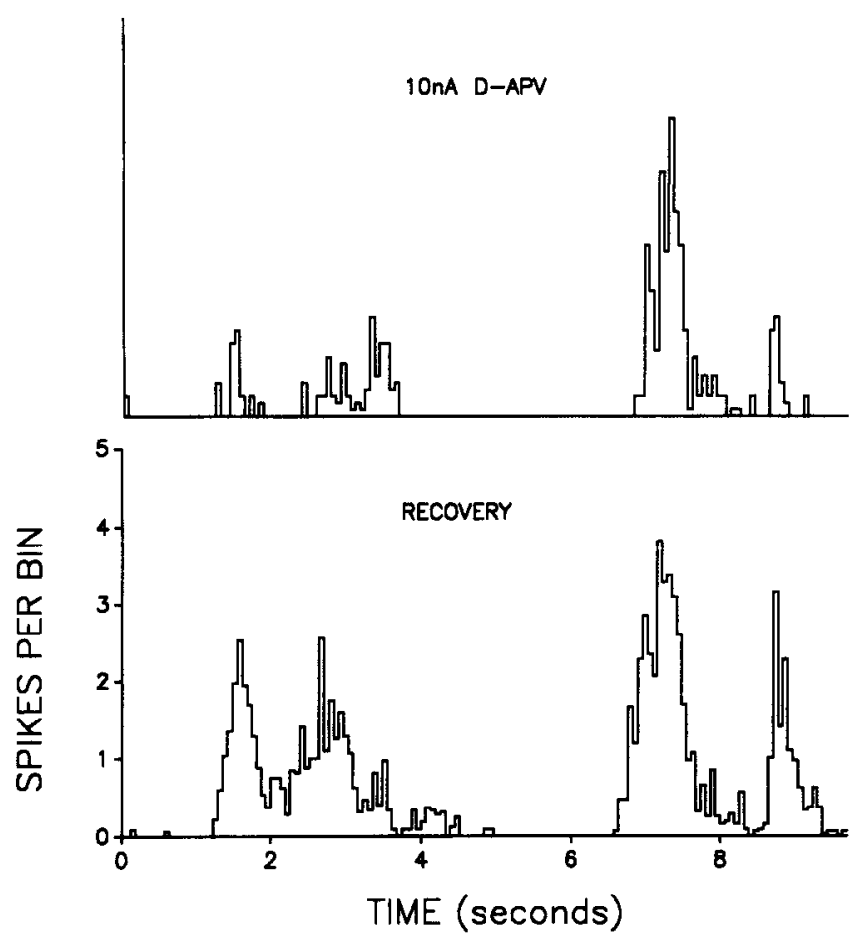

Layer IV 32 Days
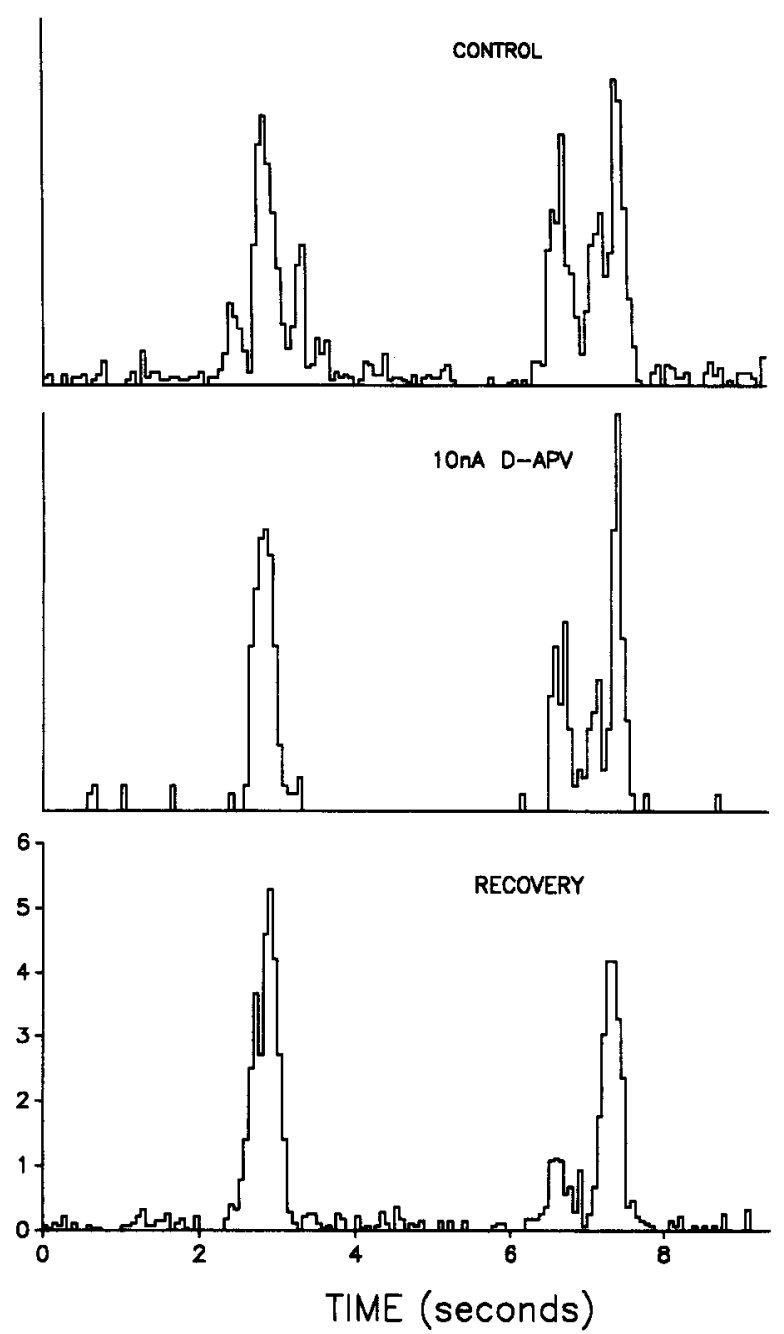

Figure 5. Effect of APV on layer IV cells in kittens. Control, test, and recovery peristimulus time histograms for a $20 \mathrm{~d}$ (left) and a $32 \mathrm{~d}$ (right) layer IV cell. Details are the same as in Figure 2, except that control right is an average of 24 stimuli over $6 \mathrm{~min}$. Bin width, $50 \mathrm{msec}$. Left, $20 \mathrm{~d}$. Response was reduced to $36 \%$ of control; recovery to $80 \%$ occurred within $8 \mathrm{~min}$. A second trial (not shown) caused a reduction to $37 \%$ of control. Right, $32 \mathrm{~d}$. The visual response was reduced to $83 \%$ of control (insignificant decrease). However, the spontaneous activity was significantly affected, falling to $19 \%$ of control. Spontaneous activity recovered to $90 \%$ of control within $4 \mathrm{~min}$.

independent of age, APV reduced visual responses of all layer II/III neurons to an average of $30 \%( \pm 20 \%)$ of control levels $($ median $=22 \%, \mathrm{IQR}=22 \%, n=55)$.

\section{Layer IV}

Whereas there were almost no cells in layer IV of adult cortex where visual responses were significantly reduced by APV (1/ 10 ), nearly half the cells in layer IV of the 28-35 d group were sensitive to APV. Of the 5 of 11 cells which showed some susceptibility in the 4-week group, visual responses were reduced by APV to between 41 and $76 \%$. There was a trend for visual responses to be affected more in 4-week animals than in adults, and more in 3-week animals than in 4-week. This trend is reflected in the mean values of the distributions for each age group: for adults the mean of the distribution was $94 \%$, for 4 -week kittens $78 \%$, and for 3-week kittens $43 \%$.

Figure 5 shows examples of the effect of APV on 2 layer IV cells, one from a 20-d animal (left) and the other from a 32-d animal (right). Both cells were classified as simple. The cell in the 20-d animal showed signs of receptive field immaturity (a large 5-degree receptive field, wide orientation tuning, and a multiple peak peristimulus time histogram). The visual response was significantly reduced to $36 \%$ of its original level. The triplepeak response to one direction of stimulus movement was altered more than the response to the reverse direction. In contrast, only the spontaneous activity was affected by APV in the 32-d cell (reduction to 19\% of control), and the visual response was not significantly altered.

\section{Layers $V$ and $V I$}

A similar trend to that found in layer IV cells was evident in layer V and VI cells. Figure 6 shows the effect of APV on the level of visual response for neurons grouped into layer II/III cells and layer IV/V/VI cells. Whereas the sensitivity of the layer II/III group does not change with age, there is a trend for visual responses in cells of deeper layers to become less sensitive to APV treatment with increasing age. Layer V cells constitute only a small percentage of the total in adult and 4-week animals. 


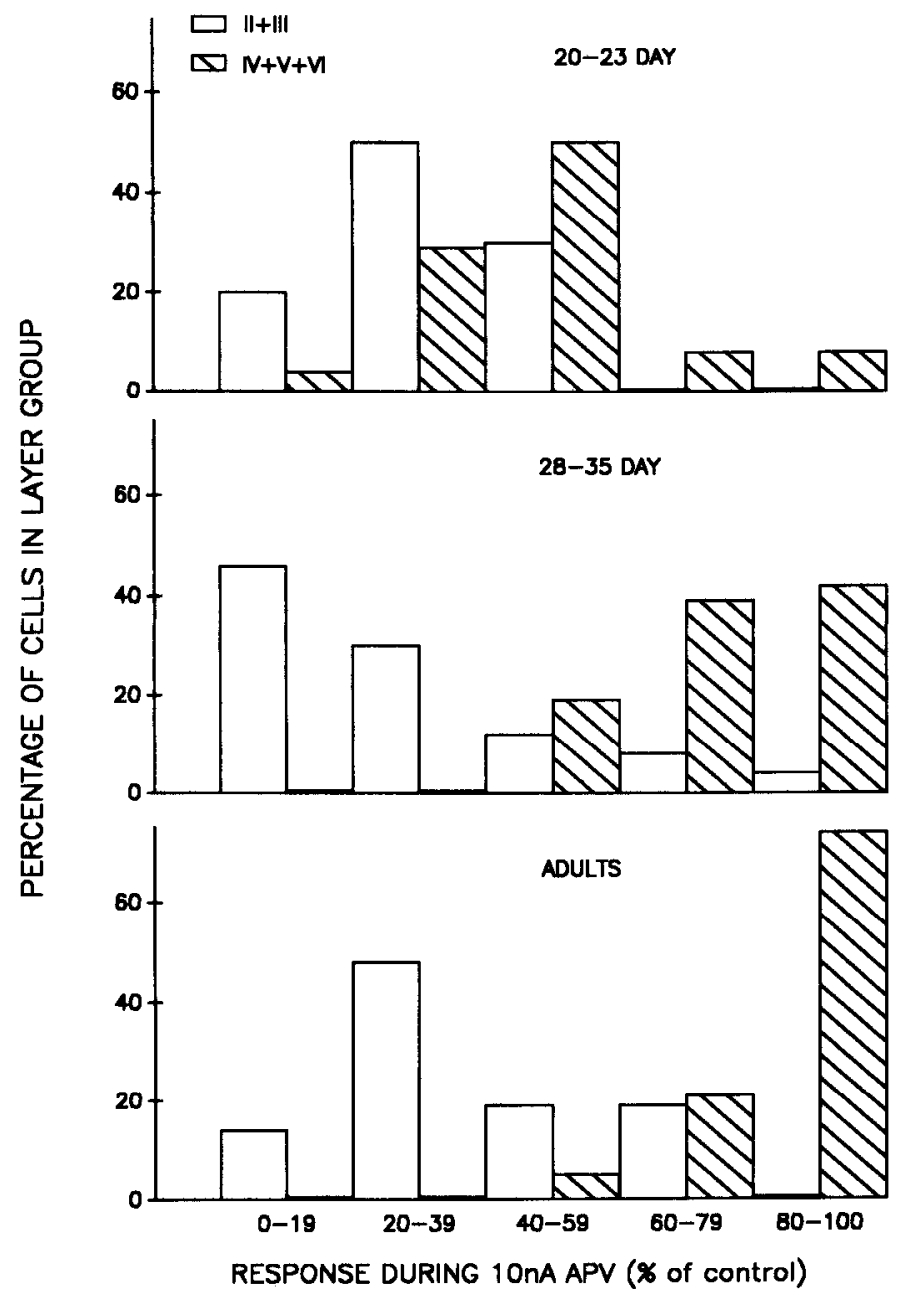

Figure 6. Effect of APV on visual responses in layers II/III versus layers IV/V/VI for different ages. Open bars represent layers II/III; crosshatched bars represent layers IV/V/VI. The height of each bar represents the proportion of cells for which the visual response was decreased to the level indicated on the abscissa. Each bar is expressed as a percentage of the cells within that group (II/III or IV/V/VI); e.g., $50 \%$ of layer IV/ III cell visual responses were reduced to between $20-39 \%$ of control in the 20-23 d age group. Top, 20-23 d age group. The distributions for superficial and deep layers overlap. Middle, 28-35 d age group. The distributions for superficial and deep cells are largely separate. Bottom, Adult age group. As with the 28-35 d kittens, the distributions are largely separate. Note the trend for layer IV/V/VI cells to become less sensitive (shift right) with age, unlike the layer II/III cells.

It is possible that if more layer $V$ cells were studied at these ages they would reveal a different pattern of development; however, layer IV and layer VI cells do seem to show a similar trend across this age range.

\section{Spontaneous activity}

Spontaneous activity (i.e., spike activity not correlated with stimulation of the visual field) was generally reduced by APV more than was the visual response. Figure 7 shows a plot of reduction in spontaneous activity versus reduction in visual response. Each point represents a single drug trial on an individual cell. Hence, neurons which showed no decrease in visual response are represented along the top line of the graph: as can be seen, all of these cells showed some reduction in spontaneous activity. The line at 45 degrees represents equal effect on spontaneous activity and visual response. Most points $(83 \%)$ lie above this line, indicating that spontaneous activity was almost always affected more than visual response during APV application. Figures 2 and 5 also show the differential effect on spontaneous activity in a layer VI cell and a layer IV cell, respectively. There was a tendency for this effect to be less marked in layer II and III cells since the visual response was usually reduced by as much as was the spontaneous activity.

A complementary result was obtained with iontophoresis of NMDA. The spontaneous activity of all cells studied was increased by NMDA at ejecting currents between 5-30 nA. There were no overt differences between layers or ages. However, visual responses were only occasionally increased by NMDA, and were often unaffected despite NMDA increasing the spontaneous activity 2- to 3-fold. This may be related to the observation that APV reduced the spontaneous activity of many neurons more than it did their visual responses. Both NMDA and APV had larger effects on spontaneous than visually evoked activity in these cases.

It was noted that most cells could not endure long periods of NMDA application (55 of 57 tested over long durations). Excitations exceeding 2 or $3 \mathrm{~min}$ were usually avoided as they resulted in silencing the cell for several minutes thereafter.

\section{Factors not correlated with APV sensitivity}

\section{Receptive field properties}

No correlation was found between receptive field type and sensitivity of the visual response to APV. One might have expected some correlation with simple versus complex cells since these constitute different percentages of the populations in supragranular and granular layers. However, layer IV contained some cells which were clearly complex and many others which were not clearly simple or complex by classical criteria. Superficial layers contained a significant number of neurons which showed just "off" or just "on" responses to stationary stimuli, and these were not classified as complex cells.

In some cases we tested the effect of APV on the orientation tuning of cells. In these cases APV either had little effect or narrowed the orientation tuning by 4-8 degrees. At present we cannot explain this effect, which is the subject of further investigation. There was no correlation between width of orientation tuning and sensitivity of the response to APV for either unidirectional or bidirectional cells. The distributions of orientation tuning were comparable for kittens and adults, most cells responding to between 75 and 115 degrees. However, half-widths were not measured, and tuning estimates were largely subjective.

There was a marked difference in ocular dominance (OD) in kittens compared with cats. Adult cats were more monocular $(\mathrm{BI}=0.39)$ than kittens $(\mathrm{BI}=0.63)$. Therefore, just as there was a difference between the effect of APV in adults and kittens, there was also a correlation between OD and sensitivity to APV. However, treated independently, there was no correlation between OD and sensitivity to APV within the kitten or within the adult groups. One might have expected some correlation since layers IV and VI are regarded as more monocular and these were also the least sensitive to APV. But we found no overt differences in binocularity between layers II and III compared with layers IV and VI within age groups. Both were binocular in kittens and relatively monocular in adults.

\section{Visual response magnitude}

There was no correlation between the degree to which the visual response of an individual cell was reduced by APV and the 


\section{EFFECT OF APV ON CORTICAL ACTIVITY}

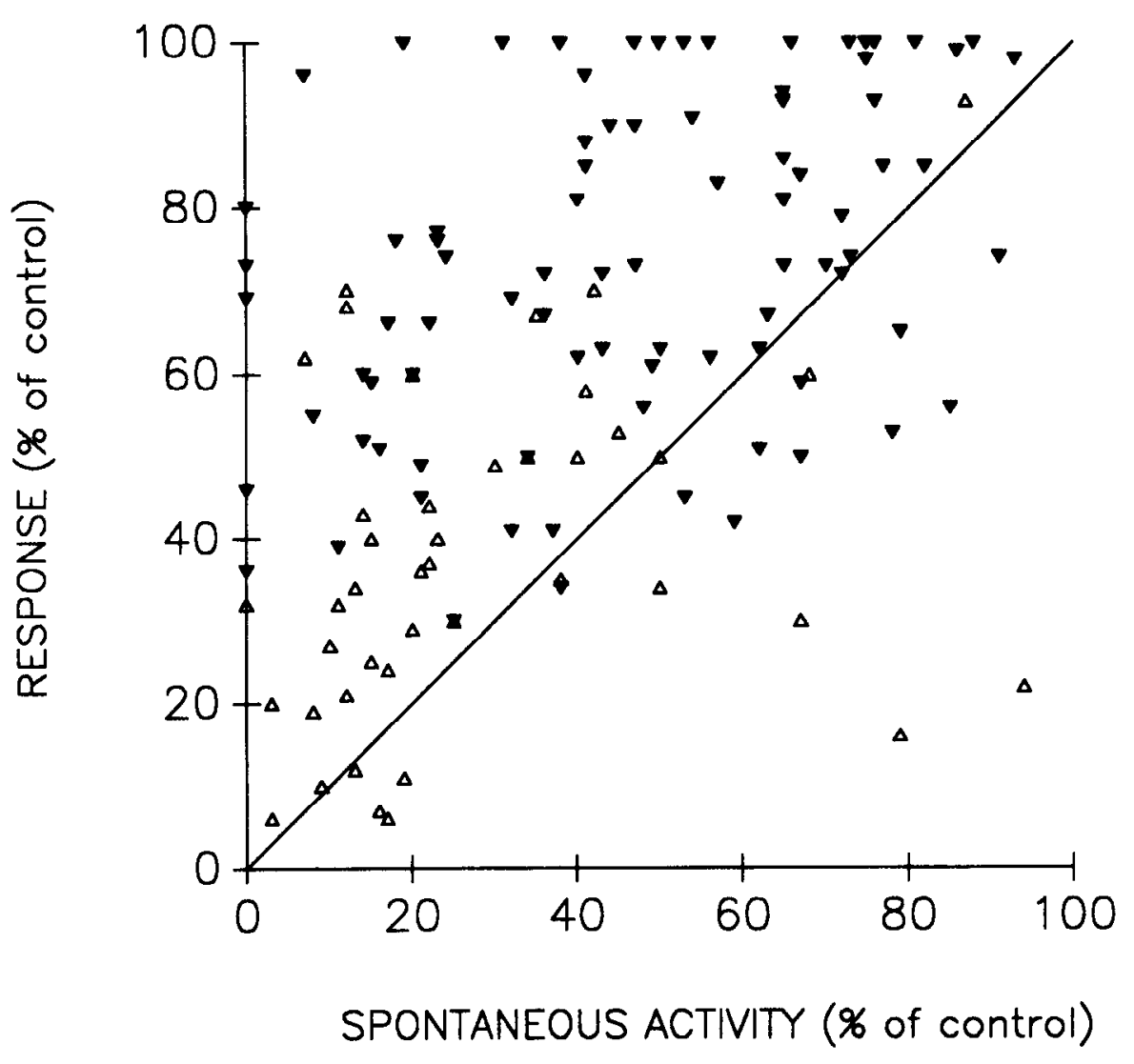

Figure 7. Comparison of the effect of APV on spontaneous versus visually evoked activity. Each point represents data from a single $10 \mathrm{nA}$ APV trial. The visual response during APV application expressed as a percentage of the control value forms the $Y$ coordinate of each point, and the spontaneous activity the $X$ coordinate. Where equal reductions in response and spontaneous activity occurred, points fall on the 45 degree line. Most points lie above this line, indicating a greater effect of APV on spontaneous activity (when expressed as a percentage of control values). Open triangles represent layer II/ III cells; inverted filled triangles represent layer IV/V/VI cells. Data are combined for all age groups.

average firing rate of the neuron during control stimulation. The correlation coefficient was 0.22 for a straight line through data for 90 cells (fit by least squares). The avcragc control firing ratc was equivalent for kittens and cats (difference between means: $4.5 \pm 9.8 \mathrm{t}$ spikes/sec by the Student's $t$ test). When tested with the optimal visual stimulus, most cells produced an average of 17 spikes per second per stimulus, where the firing rate was averaged over the entire response duration, typically $1-2 \mathrm{sec}$. Peak firing rates were obviously higher, between 20 and $200 \mathrm{~Hz}$ averaged over $50 \mathrm{msec}$. These results may reflect a bias toward oversampling cells with powerful responses, because for these experiments it was imperative to study cells with stable response properties. Based on recent experiments in which contrast was varied for individual neurons (not reported here), the contrast used in the present experiments would have produced a response toward the top end of the linear portion of the contrast response curve.

\section{Discussion}

The technique used in this study was considered to yield results which apply to NMDA receptors rather than other glutamate receptor subtypes because (a) responses were generally not completely suppressed by APV, suggesting that the dose used was not blocking all glutamate receptors; (b) kainate- and quisqualate-induced excitations were not affected by APV at the dose used, although it abolished equipotent NMDA-induced exci- tations; (c) the dose used affected cells in different layers differently, yet affected cells in the same layers of different animals the same way; and (d) layer IV cells were the least responsive to this dose of APV and yet kynurenic acid abolishes visual responses and electrically evoked action potentials in this layer (Tsumoto et al., 1986).

In a previous study it was found that neurons in the visual cortex of kittens were affected by APV more than were those in adults (Tsumoto et al., 1987). In contrast, we found that 28-35 $\mathrm{d}$ kittens were similar to adults in this respect. Our results showed a much larger difference between 20-23 d animals and adults than between 28-35 d animals and adults. The discrepancy cannot be explained by the former study having concentrated on 20-23 d kittens more than on kittens older than $28 \mathrm{~d}$. The explanation seems to be that the proportion of cells recorded in layers II/III was smaller in that study than in this and that neurons in different layers were combined for comparison, whereas in this study they were analyzed separately. Layers II/ III constituted $27 \%$ of the total sample in kittens (Hagihara, personal communication) compared with $41 \%$ in this study, and $18 \%$ in the adults (Hagihara et al., 1988) compared with $51 \%$ in this study. The difference in sampling is probably attributable to differences in the microelectrodes and the anesthetic regime. Since the results in layers II/III were similar across all age groups, a smaller contribution from these layers to the total sample would tend to accentuate the difference between kittens and adults when combining data from all layers. 


\section{Receptor location and pathways}

So far, NMDA receptor autoradiography has been confined to adult rats. Receptors are present in all cortical layers, but at higher densities in superficial cortex (Greenamyre et al., 1985; Cotman et al., 1987). Preliminary autoradiographic evidence from our laboratory indicates the same to be true of adult cats. The autoradiographic evidence is therefore in accord with the physiological data reported here. While NMDA and APV both had some effect on spontaneous activity in all layers, APV decreased visual responses only in layers II and III, which is the area of highest NMDA receptor density.

It is important to emphasize that APV affected cells in all layers. However, the nature of the effect differed for superficial and deep layers. Visual responses were affected in layers II and III, and spontaneous activity in layers IV, V, and VI. Hence, APV was able to diffuse sufficiently to affect some NMDA receptors in all cases. The inability of APV to affect visual responses therefore was not due to inadequate diffusion in layers IV, V, and VI. Even when higher ejecting currents and longer durations of application were used they failed to induce any further effect on the visual response, whereas just the standard dose adequately reduced spontaneous activity. These results stand in contrast to those obtained using kynurenic acid (a nonspecific glutamate antagonist) applied to visual cortical neurons using the same iontophoretic technique. Kynurenic acid was found to consistently reduce visual responses in all layers of cortex (Tsumoto et al., 1986; Hagihara et al., 1988). While it is possible that the apical dendrites of layer V and VI cells were unaffected by our technique, it is unlikely that the differences found between layers II/III and layer IV can be attributed to inadcquate coverage of the dendrites with antagonist in layer IV. Our results suggest that NMDA receptors in deeper layers of the adult animal are not directly involved in the sensory responses of these neurons, which raises the question of what role they play in normal function. They may be functionally redundant or, alternatively, receive inputs from cells which are not activated by specific sensory stimuli. The latter would present a case similar to that in somatosensory cortex, where APV was found to block inputs from the intralaminar nuclei without affecting the sensory drive to layer V neurons (Fox and Armstrong-James, 1986).

Based on reports to date, all visual cortical pathways that appear to be glutamatergic arise from cells that respond to specific sensory stimuli. Pathways which either transport D-[ $\left.{ }^{3} \mathrm{H}\right]-$ aspartate and/or evoke EPSPs which are blocked by glutamate antagonists include geniculocortical projections to layer IV (Tsumoto et al., 1986), claustral projections to layer IV (Fischer et al., 1982; Boyapati and Henry, 1985; LeVay, 1986), corticogeniculate cells in layer VI which send collaterals to layers IV, V, and VI (Baughman and Gilbert, 1981; Katz, 1987), layer V corticocollicular cells which send collaterals to layers II/III and VI (Lund Karlsen and Fonnum, 1978; Matute and Streit, 1985; Huettner and Baughman, 1988), and layer III projections to layer V (Jones and Baughman, 1987). If these pathways are glutamatergic, they presumably terminate on kainate or quisqualate receptors in layers IV, V, and VI of adults, because APV did not reduce the visual responses of these cells. Less is known of the transmitter(s) in the sensory pathways to layers II/III. However, because APV blocks sensory responses in these layers, they may be glutamatergic. Layer IV cells are known to project to superficial layers (Gilbert and Wiesel, 1981) where they presumably provide a large visual input. In addition, there is a geniculocortical projection to lower layer III (Humphrey et al., 1985) which may be glutamatergic (see above). A subset of layer III callosal projections may be glutamatergic by analogy with the somatosensory system (Barbaresi et al., 1987).

\section{Mechanisms for plasticity}

As discussed above, glutamatergic pathways in A17 generally carry visual information and can activate NMDA receptors in specific layers at certain ages. What are the implications of these observations for the theory that NMDA receptors are involved in plasticity? Previous theories on transmitter/receptor systems involved in plasticity have concerned "gate mechanisms." A gate mechanism is one in which the synapses gating plasticity do not themselves undergo modification. Three systems have been proposed to gate plasticity in the visual cortex: the noradrenergic system (Kasamatsu et al., 1979; Imamura and Kasamatsu, 1988), the intralaminar system (Singer, 1982), and the cholinergic system (Bear and Singer, 1986). The neurons giving rise to these systems do not receive direct inputs from visual pathways, nor do they respond to specific visual stimuli. Hence, while they may gate when synapse modification occurs, they cannot determine the exact nature of the modification.

There is a major difference between gating mechanisms and the NMDA receptor mechanism proposed for long-term potentiation (LTP) in the hippocampus (Collingridge et al., 1983; Collingridge and Bliss, 1987). In the case of the NMDA receptor mechanism, the synapses activated by the stimulus themselves undergo modification; their modification is "self determined." This is a necessary attribute of a mechanism controlling plasticity in the visual cortex because it is the visual stimulus (or lack of it) which specifies the nature of the modification. For example, binocularity is not affected by orientation deprivation and orientation specificity is not affected by monocular deprivation (Wiesel and Hubel, 1963; Blakemore and Van Sluyters, 1975).

Glutamatergic cells, as discussed above, generally transmit visual information, and where they lie presynaptic to NMDA receptors the "self-deterministic" plasticity mechanism could operate. On the basis of results reported here, self-deterministic plasticity could apply in all layers of the 20-23 d kittens but only in layers II and III of the adult. However, where NMDA receptors are activated by nonsensory inputs (Fox and Armstrong-James, 1986), NMDA receptors also could have a gating effect on plasticity.

It has been shown that APV is capable of blocking the ocular dominance shift in 4-8 week kittens (Kleinschmidt et al., 1987). However, since APV also allowed a decrease in direction specificity, which also occurs under conditions of binocular deprivation (Wiesel and Hubel, 1965; Mower et al., 1981) and retinal TTX blockade (Stryker and Harris, 1986), there is some question as to whether it acts by blocking visual activity. Our results indicated that visual responses of supragranular layer neurons are significantly depressed by APV at doses specific to NMDA receptors. Therefore, in those layers APV produces a similar outcome to blocking visual input. However, arguing from our results, the majority of layer IV, V, and VI neurons should have retained visual responses (although secondary effects may have occurred owing to a reduction in input from layers II and III to layers IV, V, and VI). Our results apply only to local 2-min applications of APV; there may be considerable differences in its effect when applied for a sustained period over a wide area, as was the case for the plasticity experiments of Kleinschmidt 
et al. (1987). For example, when infused by minipump APV blocked cortical activity over the first few days of perfusion (Miller et al., 1987). In order to understand how APV infusion affects plasticity, it will be necessary to separate out effects in different layers. Where possible, it will be advantageous to separate out the effect of reducing visual responses from specific effects on plasticity.

\section{Correlation with critical periods}

\section{Layers $I I$ and III}

The finding that visual stimuli powerfully activate NMDA receptors in layers II and III but not those in layers IV, V, and VI at the peak of the critical period (28-35 d) does not correlate with anything presently known about a difference in plasticity between these layers. If the presence of an NMDA mechanism were a factor which produced plasticity, one might expect less plasticity in layers IV, V, and VI than in supragranular layers at this age. Most studies have reported that the critical period of layer IV ends earlier than that of extragranular layers but have not noted a difference between layers II and III compared with layers V and VI (LeVay et al., 1980; Mower et al., 1985; Swindale, 1988). There is only a little evidence to suggest greater plasticity in layers II and III compared with other layers. Singer et al. (1981) found that orientation columns in layers II and III could expand to merge with one another in kittens whose vision had been restricted to vertical orientations. In contrast, layer IV orientation columns were less affected and the original columnar pattern tended to project unchanged to layers V and VI. If LTP is considered to be related to plasticity, the results of Komatsu et al. (1988) may also be relevant. They found LTP to be greatest in layers II and III of 29-35 d kitten visual cortex, especially the polysynaptic late currents. They did not test whether NMDA receptors were involved. Where it was possible to determine, LTP in layers V and VI was variable or equivalent to that in layer IV.

\section{Layers $I V, V$, and $V I$}

In this study, we found that the NMDA receptor component of the visual response decreased with age in layers IV, V, and VI. The critical period for layer $\mathrm{V}$ and VI neurons ends later than 4 months (Mower et al., 1985) and therefore appears to outlast the period when NMDA receptors are directly activated by visual stimuli. The critical period for layer IV neurons in the cat is not known with any precision but, by analogy with layer IVC of the monkey, presumably lasts beyond the end of geniculocortical segregation, which finishes at about 5-6 weeks in cats. The presently known upper limit for plasticity in layer IV is 16 weeks (Mower et al., 1985). As with layers V and VI, the critical period of layer IV also seems to exceed the period during which NMDA receptors exert a peak influence on visual responses in this layer. However, it is still conceivable that the smaller NMDA component of the visual response is sufficient for plasticity or that a gate mechanism could be involved (see above).

The only developmental factor which seems strongly time correlated with visual activation of NMDA receptors is segregation of geniculocortical axons in layer IV. It was found that there was a significant NMDA receptor contribution to the visual response in layer IV neurons of 20-23 d kittens (median $=62 \%$ ), yet approximately one week later there was none in half the cells and only a minor component in the remainder. The decline in NMDA receptor potency in layer IV corresponds with the end of geniculocortical afferent segregation. Segregation starts later than $15 \mathrm{~d}$ and is largely finished at $39 \mathrm{~d}$ (LeVay et al., 1978). Visual responses were suppressed by APV in $20 \mathrm{~d}$ animals but were significantly less in $35 \mathrm{~d}$ animals. It is known that retinal signals are essential for geniculocortical afferent segregation in A17 of the cat (Stryker and Harris, 1986), and visual experience is reported to be necessary for segregation by some workers (Swindale, 1981, 1988; Mower et al., 1985), though only for complete segregation by others (Stryker and Harris, 1986). Therefore, since NMDA receptors contribute to the visual response of layer IV neurons over this time period it is possible that NMDA receptors are necessary for segregation. This would be analogous to the case of the 3-eyed-frog tectum where retinal afferents from 2 eyes can be prevented from continuing to segregate by administration of APV (Cline et al., 1987).

In conclusion, it was found that supragranular layer neurons exhibited sensory-evoked NMDA receptor activity beyond the term currently considered to be their critical period, while infragranular layers seemed to lose sensory-evoked NMDA activity before the end of the term conventionally considered to be their critical period. Although it is possible that superficial layers remain plastic in adults, it seems likely, based on current evidence, that NMDA receptors primarily serve a role in visual processing in layers II/III. However, there was a reasonable age correlation between the period during which NMDA receptors form a large component of the visual response in layer IV and the period of geniculocortical segregation. Further experiments will be necessary to determine whether NMDA receptors are necessary for segregation to occur.

\section{References}

Armstrong-James, M., K. Fox, and J. Millar (1980) A method for etching the tips of carbon fibre microelectrodes. J. Neurosci. Methods 2: $431-432$.

Armstrong-James, M., K. Fox, Z. L. Kruk, and J. Millar (1981) Quantitative iontophoresis of catecholamines using multibarrel carbon fibre microelectrodes. J. Neurosci. Methods 4: 385-406.

Artola, A., and W. Singer (1987) Long-term potentiation and NMDA receptors in rat visual cortex. Nature 330: 649-652.

Barbaresi, P., M. Fabri, F. Conti, and T. Manzoni (1987) D-[ $\left.{ }^{3} \mathrm{H}\right]-$ Aspartate retrograde labelling of callosal and association neurons of somatosensory areas I and II of cats. J. Comp. Neurol. 263: 159-178.

Baughman, R. W., and C. D. Gilbert (1981) Aspartate and glutamate as possible neurotransmitters in the visual cortex. J. Neurosci. 1:427439.

Bear, M. F., and W. Singer (1986) Modulation of visual cortical plasticity by acetylcholine and noradrenaline. Nature 320: 172-176.

Berman, N., and N. W. Daw (1977) Comparison of the critical period for monocular and direction deprivation in cats. J. Physiol. 265: 249259.

Blakemore, C., and R. C. Van Sluyters (1975) Innate and environmental factors in the development of the kitten's visual cortex. J. Physiol. 248: 663-716.

Boyapati, I., and G. H. Henry (1985) The character and influence of the claustral pathway to the striate cortex of the cat. Exp. Brain Res. 61: 141-152.

Cline, H. T., E. A. Debski, and M. Constantine-Paton (1987) N-Methyl-D-aspartate receptor antagonist desegregates eye-specific stripes. Proc. Natl. Acad. Sci. USA 84: 4342-4345.

Collingridge, G. L., and T. V. P. Bliss (1987) NMDA receptors-their role in long-term potentiation. T.I.N.S. 10: 288-293.

Collingridge, G. L., S. J. Kehl, and H. McLennan (1983) Excitatory amino acids in synaptic transmission in the Schaffer collateral-commissural pathway of the rat hippocampus. J. Physiol. 334: 33-46.

Cotman, C. W., D. T. Monaghan, O. P. Ottersen, and J. Storm-Mathisen (1987) Anatomical organization of excitatory amino acid receptors and their pathways. T.I.N.S. 10: 273-280. 
Fischer, B. O., O. P. Ottersen, and J. Storm-Mathisen (1982) Axonal transport of D- $\left[{ }^{3} \mathrm{H}\right]$-aspartate in the claustrocortical projection. Neurosci. (suppl.) 7: S69.

Fox, K., and M. Armstrong-James (1986) The role of the anterior intralaminar nuclei and $\mathrm{N}$-methyl $\mathrm{D}$-aspartate receptors in the generation of spontaneous bursts in rat neocortical neurones. Exp. Brain Res. 63: 505-518.

Freeman, R. D., and A. B. Bonds (1979) Cortical plasticity in monocularly deprived immobilized kittens depends on eye movement. Science 206: 1093-1095.

Gilbert, C. D., and T. N. Wiesel (1981) Laminar specialisation and intracortical connections in cat primary visual cortex. In The Organisation of the Cerebral Cortex, F. O. Schmitt, F. G. Worden, G. Adelman, and S. G. Dennis, eds., pp. 163-191, MIT Press, Cambridge, MA

Greenamyre, J. T., J. M. M. Olson, J. B. Penney, and A. B. Young (1985) Autoradiographic characterization of N-methyl-D-aspartate-, quisqualate-, and kainate-sensitive glutamate binding sites. J. Pharmacol. Exp. Ther. 233: 254-263.

Hagihara, K., T. Tsumoto, H. Sato, and Y. Hata (1988) Actions of excitatory amino acid antagonists on geniculocortical transmission in the cat's visual cortex. Exp. Brain Res. 69: 407-416.

Huettner, J. E., and R. W. Baughman (1988) The pharmacology of synapses formed by identified corticocollicular neurons in primary cultures of rat visual cortex. J. Neurosci. 8: 160-175.

Humphrey, A. L., M. Sur, D. J. Ulrich, and S. M. Sherman (1985) Projection patterns of individual $\mathrm{X}$ - and $\mathrm{Y}$ - cell axons from the lateral geniculate nucleus to cortical area 17 in the cat. J. Comp. Neurol. 233: $159-189$

Imamura, K., and T. Kasamatsu (1988) Acutely induced shift in ocular dominance during brief monocular exposure: Effects of cortical noradrenaline infusion. Neurosci. Lett. 88: 57-62.

Jones, K. A., and R. W. Baughman (1987) NMDA and non-NMDA mediated components of synaptically evoked input from layer $2 / 3$ cells to pyramidal cells in layer $\mathrm{V}$ of rat visual cortex. Soc. Neurosci. Abstr. 13: 1560.

Kasamatsu, T., J. D. Pettigrew, and M. Ary (1979) Preservation of binocularity after monocular deprivation in the striate cortex of kittens treated with 6-OHDA. J. Comp. Neurol. 185: 163-182.

Katz, L. (1987) Local circuitry of identified projection neurons in cat visual cortex brain slices. J. Neurosci. 7: 1223-1249.

Kleinschmidt, A., M. F. Bear, and W. Singer (1987) Blockade of "NMDA" receptors disrupts experience-dependent plasticity of kitten striate cortex. Science 238: 355-358.

Komatsu, Y., K. Fujii, J. Maeda, H. Sakaguchi, and K. Toyama (1988) Long-term potentiation of synaptic transmission in kitten visual cortex. J. Neurophysiol. 59: 124-141.

Kruk, Z. L., M. Armstrong-James, and J. Millar (1980) Measurement of the concentration of 5-hydroxytryptamine ejected during iontophoresis using multibarrel carbon fibre microelectrodes. Life Sci. 27: 2093-2098.

LeVay, S. (1986) Synaptic organization of claustral and geniculate afferents to the visual cortex of the cat. J. Neurosci. $6: 3564-3575$.

LeVay, S., M. P. Stryker, and C. J. Shatz (1978) Ocular dominance columns and their development in layer IV of the cat's visual cortex. J. Comp. Neurol. 179: 223-244.

LeVay, S., T. N. Wiesel, and D. H. Hubel (1980) The development of ocular dominance columns in normal and visually deprived monkeys. J. Comp. Neurol. 191: 1-51.

Lund Karlsen, R., and F. Fonnum (1978) Evidence for glutamate as a neurotransmitter in the corticofugal fibres to the dorsal lateral geniculate body and the superior colliculus in rats. Brain Res. 151:457467.

Matute, C., and P. Streit (1985) Selective retrograde double labeling with D- $\left[{ }^{3} \mathrm{H}\right]$-aspartate in afferents to the superior colliculus. J. Comp. Neurol. 241: 34-49.

Miller, K. D., B. Chapman, and M. P. Stryker (1987) Infusion of an NMDA-receptor antagonist blocks visually driven cortical activity in cat visual cortex. Soc. Neurosci. Abstr. 13: 357.

Mower, G. D., D. Berry, J. L. Burchfiel, and F. H. Duffy (1981) Comparison of the effects of dark rearing and binocular suture on development and plasticity of cat visual cortex. Brain Res. 220: 255-267.

Mower, G. D., C. J. Caplan, W. G. Christen, and F. H. Duffy (1985) Dark rearing prolongs physiological but not anatomical plasticity of the cat visual cortex. J. Comp. Neurol. 235: 448-466.

Nicholson, C., and J. M. Phillips (1981) Ion diffusion modified by tortuosity and volume fraction in the extracellular microenvironment of the rat cerebellum. J. Physiol. (Lond.) 321: 225-257.

Reiter, H. O., D. M. Waitzman, and M. P. Stryker (1986) Cortical activity blockade prevents ocular dominance plasticity in the kitten visual cortex. Exp. Brain Res. 65: 182-188.

Singer, W. (1982) Central core control of developmental plasticity in the kitten visual cortex. Exp. Brain Res. 47: 209-222.

Singer, W., B. Freeman, and J. Rauschecker (1981) Restriction of visual experience to a single orientation affects the organization of orientation columns in cat visual cortex: A study with dcoxyglucosc. Exp. Brain Res. 41: 199-215.

Stryker, M. P., and W. A. Harris (1986) Binocular impulse blockade prevents the formation of ocular dominance columns in the cat visual cortex. J. Neurosci. 6: 2117-2133.

Swindale, N. V. (1981) Absence of ocular dominance patches in dark reared cats. Nature 290: 332-333.

Swindale, N. V. (1988) Absence of visual experience in promoting segregation of eye dominance patches in the visual cortex of the cat. J. Comp. Neurol. 267: 47-48.

Tsumoto, T., H. Masui, and H. Sato (1986) Excitatory amino acid transmitters in neural circuits of the cat visual cortex. J. Neurophysiol. 55: $469-483$.

Tsumoto, T., K. Hagihara, H. Sato, and Y. Hata (1987) NMDA receptors in the visual cortex of young kittens are more effective than those of adult cats. Nature 327: 513-514.

Wiesel, T. N., and D. H. Hubel (1963) Single-cell responses in striate cortex of kittens deprived of vision in one eye. J. Neurophysiol. 26: 1003-1017.

Wiesel, T. N., and D. H. Hubel (1965) Comparison of the effects of unilateral and bilateral eye closure on cortical unit responses in kittens. J. Neurophysiol. 28: 1029-1040. 